To be published in the Proceedings of the Symposium on Radiobiology of Inhaled Nuclides, heid in Richland, WA, November 9-10, 1993.

(in press, 1995)

\title{
COMPARISON OF OLD AND NEW ICRP MODELS \\ FOR RESPIRATORY TRACT DOSIMETRY
}

Bruce B. Boecker

Inhalation Toxicology

Research Institute

P.O. Box 5890

Albuquerque, NM 87185

RECEIVED

MAR 062995

OSTI

DISTRIBUTION OF THIS DOCUMENT IS UNLIMITED $W_{W}$

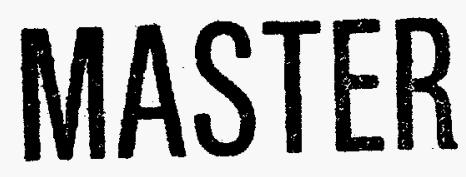

\section{Short Running Title:}

\section{ICRP Respiratory Tract Dosimetry Models}

\section{DISCLAIMER}

This report was prepared as an account of work sponsored by an agency of the United States Government. Neither the United States Government nor any agency thereof, nor any of their employees, makes any warranty, express or implied, or assumes any legal liability or responsibility for the accuracy, completeness, or usefulness of any information, apparatus, product, or process disclosed, or represents that its use would not infringe privately owned rights. Reference herein to any specific commercial product, process, or service by trade name, trademark, manufacturer, or otherwise does not necessarily constitute or imply its endorsement, recommendation, or favoring by the United States Government or any agency thereof. The views and opinions of authors expressed herein do not necessarily state or reflect those of the United States Government or any agency thereof. 


\begin{abstract}
This paper examines the historical development and application of respiratory tract dosimetry models by the International Commission for Radiological Protection, ICRP, for health protection from inhaled radioactive aerosols. Three different models are discussed, those that were included in ICRP recommendations published in 1960 and 1979, and the new ICRP Priblication 66. Basic features of these models are compared and contrasted. These features include model structure, sites and frequencies of particle deposition, processes and rates of clearance of the deposited material from the respiratory tract, and consideration of the parameters involved in these processes and how various factors can influence these parameters. All three models lead to the calculation of absorbed radiation doses with differing degrees of regional and local specificity. These calculations are achieved using different tools ranging from quick hand calculations to sophisticated computerized modeling approaches. A side-by-side review of these models indicates several important trends in respiratory tract dosimetry models, the most obvious of which is the increased complexity of each new model over the past $30+$ years. These increases reflect both the increasing size of the knowledge base derived from studies in laboratory animals and in human subjects and the need for models more broadly applicable for both occupational and environmental exposures. It is likely that future research will be directed to those key aspects of the new model having the largest uncertainties. The detailed design of the new model and its associated software provide excellent means of identifying useful research areas and using the resulting new information in organized and productive ways.
\end{abstract}




\section{DISCLAIMER}

Portions of this document may be illegible in electronic image products. Images are produced from the best available original document. 


\section{INTRODUCTION}

During the past 4 decades, the International Commission on Radiological Protection, ICRP, has published three different mathematical models to describe the deposition, clearance, and dosimetry of inhaled radioactive materials in the respiratory $\operatorname{tract}^{1,2,3}$. Models of this type, usually referred to as "lung" models, are a critical part of a radiation protection system for inhaled radioactive materials. The models make it possible to calculate the absorbed doses expected to be received by different parts of the respiratory tract and describe mathematically the expected absorption and translocation of portions of the deposited radionuclides to other organs and tissues beyond the respiratory tract.

As shown below, the structure and complexity of these models have increased with each version. These increases reflect both the expanded knowledge of the behavior and dosimetry of inhaled materials in the respiratory tract and an increased need for models having broader applications. Earlier models were used primarily for general prospective health protection planning purposes and routine workplace monitoring support. As these models have become more detailed and flexible, they have been used for site- and process-specific applications as well as for retrospective analyses of individual exposures. The following comparisons show how these models have been changed to accomplish these tasks. 


\section{STRUCTURE}

Before comparing the mathematical descriptions of particle deposition and clearance and the associated dosimetry among these models, it is important to note that the models have changed in structure, expanding from two airway regions in the 1959 model $^{1}$ to five airway regions in the 1994 models $^{3}$. As shown in Fig. 1(a), the 1959 model had a very simple structure in which the respiratory tract was divided into an upper respiratory tract, URT, and a lower respiratory tract, $\mathrm{LRT}^{1}$. No specific anatomical sites were assigned to the URT and LRT.

In 1966, the ICRP Task Group on Lung Dynamics, TGLD, published a comprehensive report on models of the deposition and retention of inhaled particles in the human respiratory tract ${ }^{4}$. This information was the basis of the dosimetric model for the respiratory tract included in the recommendations of the ICRP in its Publication $30^{2}$. In the 1979 model, the respiratory tract was divided into the three airway regions shown in Fig. 1(b), nasopharyngeal, N-P; tracheobronchial, T-B; and pulmonary, P. The N-P region extended from the anterior nares to the larynx, and the T-B region included the trachea and bronchial tree through the terminal bronchioles. The $\mathrm{P}$ region was the remaining, nonciliated gas-exchange region. In the 1966 TGLD report, it was noted that the T-B and P regions constituted what was earlier termed the LRT.

The newest model, the 1994 version shown in Fig. 2, is divided into five airway regions ${ }^{3}$. The extrathoracic airways are divided into two compartments: $\mathrm{ET}_{1}$, the anterior nose, and $\mathrm{ET}_{2}$, the posterior nasal passages, larynx, pharynx, and mouth. The bronchial region, BB, consists 
of the trachea and bronchi, and the bronchiolar region, bb, consists of the bronchioles and terminal bronchioles. The last region, the alveolar-interstitial region, AI, consists of the respiratory bronchioles, the alveolar ducts, alveoli, and the interstitial connective tissue.

\section{DEPOSITION}

The deposition portions of these models describe the expected fractional depositions of inhaled particles at different locations throughout the respiratory tract. In the definition of the 1959 model, ${ }^{1}$ it was assumed that the percentage of inhaled particles deposited in the URT, represented by $D_{U R T}$, was $50 \%$. Similarly for the $L R T$, it was assumed that $D_{L R T}$ was $25 \%$ and the remaining $25 \%$ was exhaled. The magnitude or relative distribution of particle deposition did not depend on particle size.

In the 1979 model, deposition probabilities from the TGLD report, $\mathrm{D}_{\mathrm{N}-\mathrm{P}}, \mathrm{D}_{\mathrm{T}-\mathrm{B}}$, and $\mathrm{D}_{\mathrm{p}}$, were given for the N-P, T-B, and P regions, respectively, as functions of the activity median aerodynamic diameter, AMAD, of the particle size distribution for the inhaled particles. These relationships are shown in Fig. 3. The solid lines are the recommended values, and the dashed lines indicate provisional extensions made to smaller and larger particle sizes. These recommended relationships covered about two orders of magnitude between 0.2 and $10 \mu \mathrm{m}$. Incorporation of particle size considerations and the AMAD concept was a major improvement in the health protection practices for inhaled radioactive particles. 
Our knowledge of the effects of particle size on the deposition of inhaled particles has increased substantially during the almost 3 decades since the publication of the TGLD report ${ }^{4}$. This is clearly reflected in the deposition curves in the 1994 model shown for polydisperse aerosols in Fig. $4^{3}$. Depositions in the five compartments $\left(\mathrm{ET}_{1}, \mathrm{ET}_{2}, \mathrm{BB}, \mathrm{bb}\right.$, and $\left.\mathrm{AI}\right)$ are given as functions of median particle size covering five orders of magnitude. Two different types of particle size distribution parameters are used (see footnote). The activity median thermodynamic diameter, AMTD, is used to describe the deposition for particles ranging in size from 0.001 to $1.0 \mu \mathrm{m}$. The AMAD is used to describe depositions for the size range of 0.1 to $100 \mu \mathrm{m}$. Similar deposition values are obtained for the decade of 0.1-1.0 $\mu \mathrm{m}$ using both classes of diameters. The 1994 model also considers age-related effects and particle inhalability, a measure of the probability that an airborne particle, when presented for inspiration, will enter the respiratory tract and be available for deposition. Particles larger than $10 \mu \mathrm{m}$ have relatively lower inhalability.

For each of these three models, a set of default deposition values is assigned based on default particle size parameters. The default values are to be used in the absence of site- or incident-specific particle size data. Because these default values are frequently used for calculating expected radionuclide intakes and the associated tissue doses, it is important to be aware of any changes in them and understand how those changes can affect the resulting calculations. As discussed earlier, the deposition values in the 1959 model were constants because no particle size dependence was incorporated. Therefore, these values were also the default values. In the 1979 model, a default value of $1 \mu \mathrm{m}$ AMAD was specified to determine the deposition values used in the intake and dosimetry tables given in Publication $30^{2}$. A major 
change was made in the 1994 model by specifying a default value of $5 \mu \mathrm{m}$ AMAD for occupational exposures ${ }^{3}$. As shown in Table 1, this change increased the expected deposition in $\mathrm{ET}_{1}$ and $\mathrm{ET}_{2}$ by a factor of 2.5 and decreased the corresponding depositions in the $\mathrm{BB}+\mathrm{bb}$ regions by a factor of 2.8 and the AI region by a factor of 4.7 . Another important change in the 1994 model was a separate specification for a default value for environmental exposures. This value, $1 \mu \mathrm{m}$, AMAD, recognizes the likelihood of encountering smaller particle size distributions in environmental exposures than encountered in occupational activities.

\section{CLEARANCE}

Once material has been deposited, clearance begins by several different processes. These include the release of the radionuclide by dissolution followed by absorption into the systemic circulation and the movement of particles by mechanical processes such as mucociliary activity and movement of macrophages following ingestion of intact particles. These processes and others are described in differing levels of detail in the three models considered here.

Figure 1 illustrates the compartmental structure of the a) 1959 and b) 1979 models. In the 1959 model, the URT (labeled a) is essentially an air passage in which all deposited particles are cleared quickly to the oral pharynx by mucociliary activity and subsequently swallowed to the gastrointestinal, GI, tract; no dissolution or absorption to the systemic circulation is considered. Particles deposited in the LRT are classified in only two ways: soluble or insoluble. For soluble particles, all $25 \%$ of the inhaled particles that reach the LRT are assumed 
to be absorbed quickly from compartment $b$ (no half-time specified) into the systemic circulation. For insoluble particles, $12.5 \%$ are assumed to clear from compartment $c$ to compartment a by mucociliary activity during the first $24 \mathrm{~h}$ followed by swallowing into the gastrointestinal tract. The remaining $12.5 \%$ are retained in compartment $b$ with a biological half-time of $120 \mathrm{~d}$. In this system, insoluble forms of $\mathrm{Pu}$ and $\mathrm{Th}$ were considered separately by assigning them clearance half-times of 1 and $4 \mathrm{y}$, respectively. No clearance of particles to the regional lymph nodes was included in the model.

The 1979 model shown in Figure 1(b) contained additional compartments to consider: 1) the three regions in the deposition model, N-P, T-B, and P; 2) absorption and transport of radionuclides from each of these regions; and 3) an additional clearance pathway to the tracheobronchial lymph nodes. Each compartment shown in the N-P, T-B and P regions receives a specified fraction of the particles deposited in those regions, and each represents a particular clearance process and its associated half-time. Particles deposited in the N-P and T-B regions are cleared by absorption from compartments a and $\mathrm{c}$ or by mucociliary transport from compartments $b$ and $d$ with half-times shorter than $1 \mathrm{~d}$.

In the 1979 model, most of the absorbed radiation dose to lung is received in the $\mathrm{P}$ region because of the longer retentions that occur in this region. Except for clearance from compartment $f$ with a half-time of $1 \mathrm{~d}$, clearance from compartments $e, g$, and $h$ all occur with the half-times associated with the classification of the inhaled material, i.e., $0.5,50$, or $500 \mathrm{~d}$ for Classes $\mathrm{D}, \mathrm{W}$, or $\mathrm{Y}$, respectively. In this model, the long-term clearance of radionuclides from the $\mathrm{P}$ region by either mechanical transport or dissolution-absorption processes is described 
by the same half-time, a simplification that makes the model difficult to apply to particles in which the dissolution-absorption and mechanical clearance processes lead to substantially different half-times. A related aspect of this issue is the extent to which one or more of these processes differs from the other in a time-dependent way. The 1979 model does not account for such differences. Thus, the classification of inhaled particles as Class $\mathrm{D}, \mathrm{W}$, or $\mathrm{Y}$ involves a number of assumptions and compromises that make the model difficult to use in many analyses of site- or process-specific exposure scenarios.

Figure 2 illustrates the structure and processes associated with the regional deposition and clearance of inhaled particles in the $1994 \mathrm{Model}^{3}$. Deposition in the four regions, $\mathrm{ET}\left(\mathrm{ET}_{1}+\mathrm{ET}_{2}\right), \mathrm{BB}, \mathrm{bb}$, and $\mathrm{AI}$, is shown by the large, shaded arrows. Once material is deposited in a given region, three different clearance processes act competitively on the material. These processes are shown as arrows that point a) upward representing mucociliary processes which will be followed by swallowing to the GI tract, b) left representing clearance of particles via the lymphatic system to regional lymph nodes, and c) right representing dissolution and absorption into the systemic circulation. Because these processes act independently on the regional deposit, each can be specified separately and allowed to compete against the other processes when the model is used. This approach makes it possible to use time-dependent functions to describe processes such as dissolution-absorption. Whereas $\mathrm{D}, \mathrm{W}$, and $\mathrm{Y}$ classifications were used to describe overall clearance in the 1979 model, the 1994 model uses F (fast), $M$ (moderate), and $S$ (slow) default values to classify only the dissolution-absorption process. Greater attention to the transfer of particles to regional lymph nodes is given in this 
model than earlier ICRP versions by incorporating these processes at each level in the respiratory tract, not just the AI region as was the case in the 1979 model.

Included in the clearance portion of the 1994 model are two new processes based on recent experimental studies. The first process accounts for the possibility that a fraction of the inhaled particles deposited on airway surfaces in the BB and bb regions may be cleared much more slowly than the rapid clearance once assumed. A clearance half-time of $20 \mathrm{~d}$ is assigned to this fraction. The second process modeled accounts for possible sequestration in the airway wall of a fraction of the particles deposited in the BB and bb regions. This sequestered fraction is considered to clear to the thoracic lymph nodes with a half-time of $70 \mathrm{~d}$. Both of these processes result in longer retention of some of the particles deposited in the BB and bb regions than was modeled earlier. Thus, the calculated absorbed dose to this region will increase accordingly, dependent upon the fractions ascribed to these two processes. As noted above, the incorporation of these two processes into the 1994 model is based on a limited amount of recent experimental evidence. Determination of the overall importance of these two processes and their dosimetric significance will require substantially more investigation.

\section{DOSIMETRY}

The models of deposition and clearance described above provide the mathematical means to compute activity-time integrals for various regions of the respiratory tract. These integrals can then be used in other equations to calculate absorbed doses from alpha, beta, or photon emissions from a deposited radionuclide. As was true for the deposition and clearance 
information, each succeeding version of the ICRP model has provided additional details and expanded flexibility in approaches for dosimetry calculations.

In the 1959 model, absorbed dose can only be calculated to the LRT, defined as a $1000-\mathrm{g}$ lung without the associated lymph nodes. In the 1979 model, the absorbed dose is computed for the sum of the T-B, P and lymph node regions. No provision is made for computing the absorbed dose to each tissue. Also, no provision is made for calculating absorbed dose to the $\mathrm{N}-\mathrm{P}$ region. In the 1994 model, absorbed doses can be calculated individually for $\mathrm{ET}_{1}, \mathrm{ET}_{2}$, $\mathrm{BB}, \mathrm{bb}$, and AI. Also, doses to the thoracic lymph nodes and extrathoracic lymph nodes can be computed.

Through the use of radiation weighting factors, $W_{r}$, equivalent doses can be computed. Further, by incorporating the use of tissue risk weighting factors, $W_{T}$, effective doses can be computed for summations across the respiratory tract and the other organs and tissues in the body. The degree of specification of these $W_{\mathrm{T}}$ values has changed with other model changes as shown in Table 2. Tissue risk weighting factors were not used prior to the publication of ICRP Publication $26^{5}$. Thus, no applicable information is available for the 1959 model. In the 1979 model, a value of $W_{T}=0.12$ is given for the computation of effective dose to the $T-B, P$ and lymph node regions combined. No value of $W_{T}$ is given for the N-P region, thus precluding the calculation of an effective dose to this region. An overall weighting factor of 0.12 is also used for the thoracic region in the 1994 model, but this value is then prorated equally ( 0.33 each) among the $\mathrm{BB}, \mathrm{bb}$, and $\mathrm{AI}$ regions and the thoracic lymph nodes are assigned a risk weighting of 0.001 . These latter apportionment factors have been provided to improve the quality of 
dosimetric calculations where different portions of the thoracic respiratory tract are irradiated to differing degrees as is the case with inhaled $R n$ progeny or inhaled actinide radionuclides. Also, $\mathrm{ET}_{1}, \mathrm{ET}_{2}$ and $\mathrm{LN}_{\mathrm{ET}}$ are to be added to the remainder tissues with $W_{\mathrm{T}}$ values of 0.001 , 1.0 , and 0.001 , respectively.

James $^{6}$ has compared the effective doses for several inhaled radionuclides as calculated using the 1979 and 1994 models. These results, expressed in $\mu \mathrm{Sv}$ per Bq inhaled in $1 \mu \mathrm{m}$ AMAD particles, are given in Table 3. In spite of numerous differences in the deposition, clearance, and dosimetry portions of these two models, the calculated effective doses are for the most part, only slightly different (lower) in the 1994 model. For the radionuclides considered here, the largest difference is for Class Y Pu vs. Class S Pu, where the effective dose is reduced over threefold from 60 to $16 \mu \mathrm{Sv} / \mathrm{Bq}$.

\section{USES OF THESE MODELS}

Earlier respiratory tract dosimetry models were primarily used for health protection planning purposes and routine workplace monitoring activities and analyses. In these applications, more general models, based on a broader range of assumptions and approximations, served the needs of health protection personnel quite well. As the field of health physics has matured, attention to more definitive dose assessments for site- and process-specific applications has increased. Better evaluations of past or present accidental exposures of individuals are required. Each need emphasizes the usefulness of a flexible model for evaluating radiation doses 
to the respiratory tract. The 1994 model provides a very valuable tool for this purpose. Because of the flexibility and options built into this model, it should be useful for many years in evaluating occupational and population doses using either default or situation specific factors.

As these models have become more detailed and complex, so have the computations required to use them. In the earlier models, many needed results were tabulated for ready reference. The 1994 model is available in computer software, LUDEP, ${ }^{8}$ that simplifies the use of the model and facilitates the use of "what-if ..." types of questions as well as various kinds of sensitivity analyses.

\section{CONTINUING NEEDS}

The structure and implementation of the 1994 model will make it possible to examine a number of issues in greater detail than previously possible. The model is well suited to consider the possible impact of a broad range of process- and site-specific aerosols having different characteristics, especially as related to dissolution-absorption. Although default values are available at the present time, it is likely that these process- and site-specific data will become available at later times. The question of slow clearance from the airways is an area that needs further investigation to determine its importance and the factors that may influence it. Concern over critical cells at risk can be addressed much more easily using the new model. Also, the new model facilitates further consideration of the effects of other influencing factors such as 
ethnicity, age, and health status in greater detail. Additional applications of this model to nonradioactive particles, gases, and vapors can also be addressed.

\section{$\underline{\text { SUMMARY }}$}

In summary, this comparison of three different ICRP models for respiratory tract dosimetry has illustrated several important trends. These models have increased in complexity, reflecting the growth in our knowledge of the dosimetry of inhaled radioactive materials and the various factors that can influence the doses received. More attention is being given to examining and accounting for these influencing factors such as age, ethnic groups, diseases of the respiratory tract, and the impacts of exposure to cigarette smoke and/or other air pollutants. A broader range of applicability of these models has been developed to address both occupational and environmental exposures and to consider both prospective or typical values and retrospective individual values. As these models become more detailed, greater demands are made for appropriate input data, some of which are not currently available. In this regard, these models provide useful indicators of the gaps in our knowledge and identify areas for future research. In spite of the increased complexity of the 1994 model, it should be relatively easy to use because of the availability of the LUDEP PC software for the needed computations. Dr. Bair and his committee who prepared the 1994 model and all of its supporting information are to be congratulated for providing us with such a valuable tool that should serve us well in a number of different ways for many years to come. 


\section{ACKNOWLEDGEMENT}

This research was conducted for the U.S. Department of Energy, Office of Health and Environmental Research under Contract No. DE-AC04-76EV01013.

\section{REFERENCES}

1. ICRP. Report of Committee II on Permissible Dose for Internal Radiation (1959), Health Phys. 3, (1960).

2. ICRP. Limits for Intakes of Radionuclides by Workers, ICRP Publication 30, Part 1, Ann. ICRP 2 (3/4) (1979).

3. ICRP. Human Respiratory Tract Model for Radiological Protection, Ann. ICRP 24 (1-3) (1994).

4. Task Group on Lung Dynamics. Deposition and Retention Models for Internal Dosimetry of the Human Respiratory Tract, Health Phys. 12 (2) 173-207 (1966).

5. ICRP. Recommendations of the International Commission on Radiological Protection, ICRP Publication 26, Ann. ICRP 1 (3) (1977). 
6. James, A. C. Dosimetric Applications of the New ICRP Lung Model, Internal Radiation Dosimetry (Raabe, O. G. ed.) Medical Physics Publishing (Madison, WI) ISBN 0-94483847-2, 143-160 (1994).

7. ICRP. Annual Limits on Intake of Radionuclides by Workers Based on the 1990 Recommendations. ICRP Publication 61, Ann. ICRP 21 (4) (1991).

8. Jarvis, N. S., Birchall, A., James, A. C., Bailey, M. R., and Dorrian, M-D. Personal Computer Program for Calculating Internal Doses Using the New ICRP Respiratory Tract Model, NRPB-SR264 (1993). 
Footnote Page 5

Activity Median Aerodynamic Diameter - The aerodynamic diameter of aerosol particles of median radioactive content in a collection of particles that has been aerodynamically classified. ${ }^{3}$

Activity Median Thermodynamic Diameter - The thermodynamic diameter of aerosol particles of median radioactive content in a collection of particles that has been thermodynamically classified. A log-normal distribution is usually assumed for both of these definitions. ${ }^{3}$ 


\section{Table Legends}

Table 1 Default values for regional deposition of inhaled particles used in different ICRP respiratory tract dosimetry models. Values expressed as percentages of the amount inhaled. ${ }^{1,2,3}$

Table 2 Tissue weighting factors used in different ICRP models to calculate effective doses to different regions of the respiratory tract.

Table 3 Comparison of effective doses to the respiratory tract calculated with the 1979 and 1994 ICRP respiratory tract dosimetry models. ${ }^{6}$ 


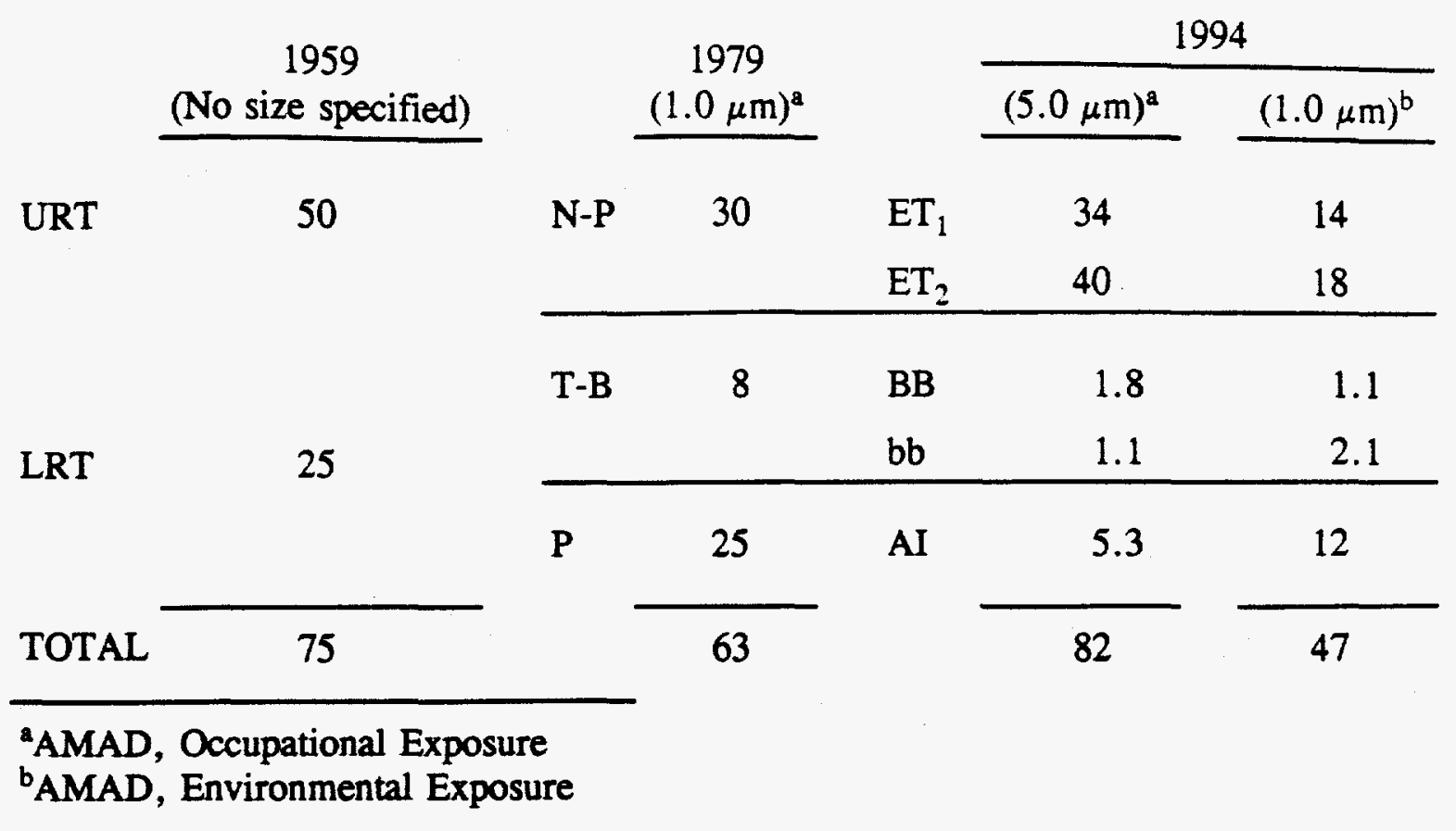




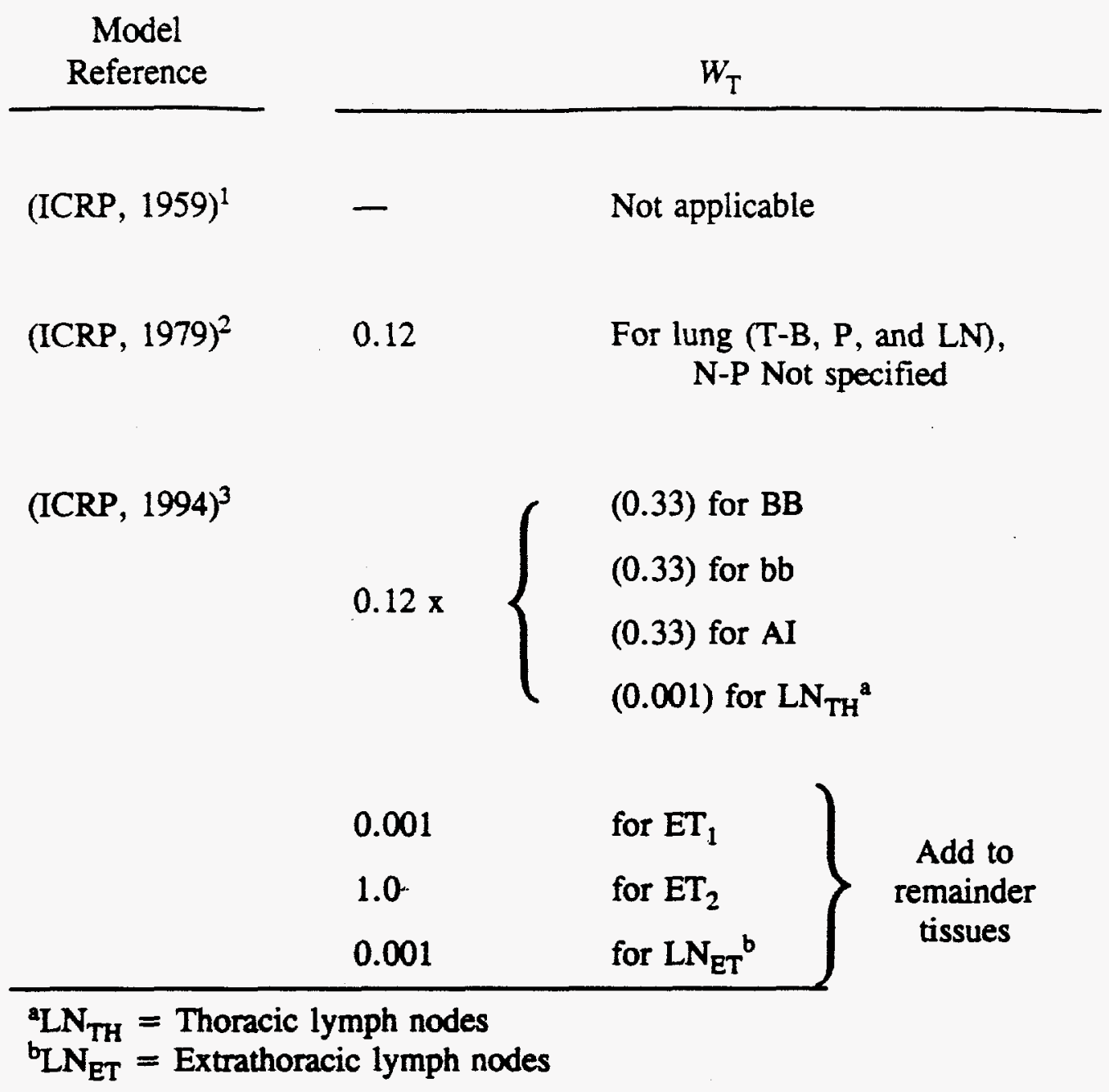




\begin{tabular}{|c|c|c|c|c|}
\hline \multirow[b]{2}{*}{ Radionuclide } & \multicolumn{4}{|c|}{$\mu \mathrm{Sv} / \mathrm{Bq}$ for $1 \mu \mathrm{m}$ AMAD } \\
\hline & \multicolumn{2}{|c|}{$\begin{array}{c}1979 \\
\text { Model }^{\mathrm{a}}\end{array}$} & \multicolumn{2}{|c|}{$\begin{array}{c}1994 \\
\text { Model }^{3}\end{array}$} \\
\hline \multirow[t]{2}{*}{${ }^{239} \mathrm{Pu}$} & W: & 70 & M: & 53 \\
\hline & Y: & 60 & S: & 16 \\
\hline${ }^{241} \mathrm{Am}$ & W: & 70 & M: & 55 \\
\hline${ }^{242} \mathrm{Cm}$ & W: & 4 & M: & 5.1 \\
\hline \multirow[t]{2}{*}{${ }^{60} \mathrm{Co}$} & W: & 0.009 & M: & 0.0084 \\
\hline & Y: & 0.06 & S: & 0.027 \\
\hline \multirow[t]{2}{*}{${ }^{144} \mathrm{Ce}-\mathrm{Pr}$} & W: & 0.05 & M: & 0.032 \\
\hline & Y: & 0.1 & S: & 0.045 \\
\hline
\end{tabular}

${ }^{\text {aRef. }} 2$ as adjusted in Ref. 7 


\section{Figure Legends}

Figure 1 Schematic representation of the compartmental structures and the pathways for deposition and clearance used in the a) $1959^{1}$ and b) $1979^{2}$ versions of the ICRP respiratory tract dosimetry models. The large, shaded arrows represent the fractional deposition of inhaled particles in various airway regions.

Figure 2 Schematic representation of the compartmental structures and the pathways for deposition and clearance used in the 1994 version $^{3}$ of the ICRP respiratory tract dosimetry model.

Figure 3 Probability of particulate deposition in different regions of the respiratory tract as functions of the activity median aerodynamic diameter, AMAD, of the particle size distribution. (Modified from Reference 2)

Figure 4 Regional deposition of inhaled particles as functions of the activity median thermodynamic diameter, AMTD, or the activity median aerodynamic diameter, AMAD for a reference worker (normal nose breather) ${ }^{3}$. 


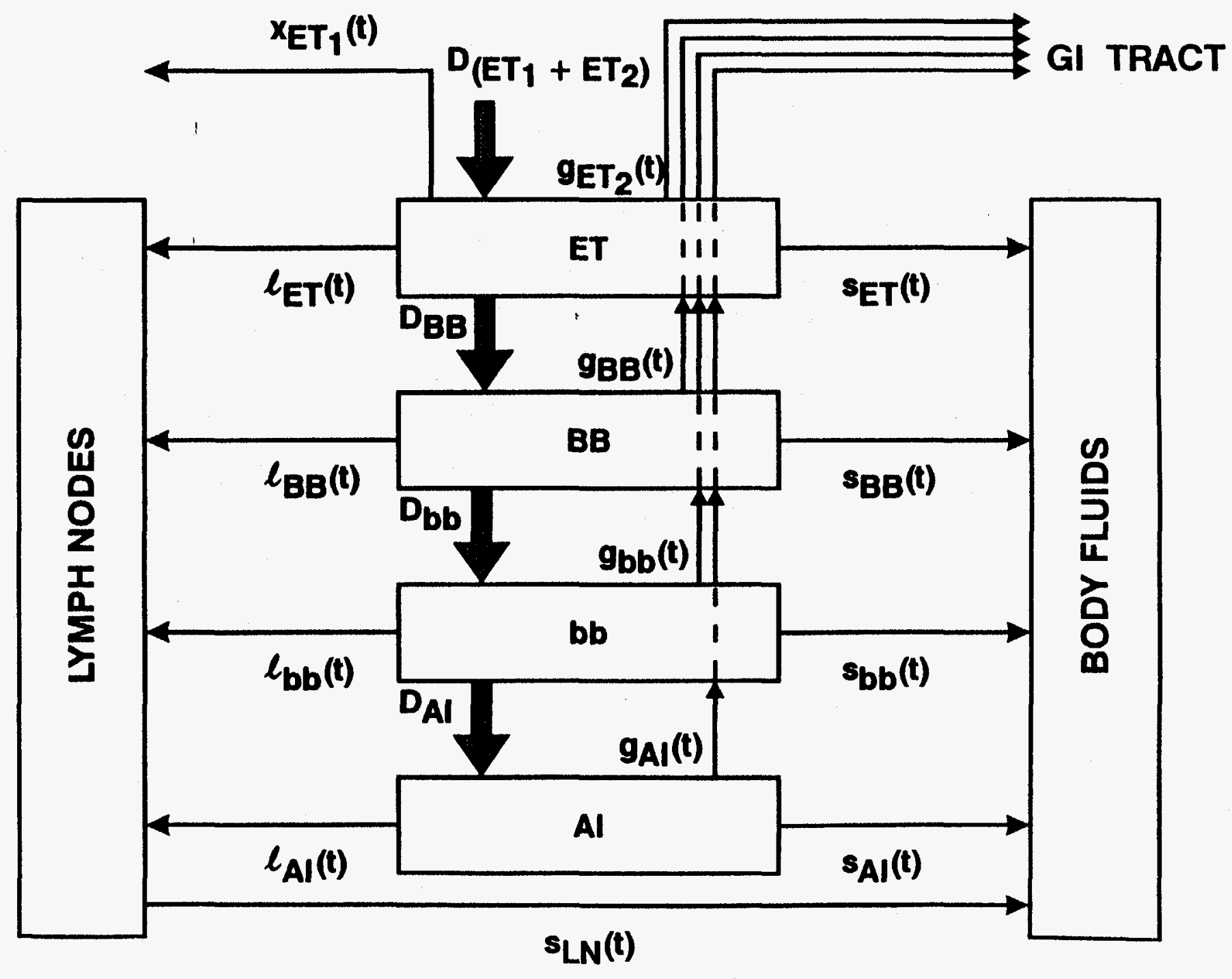



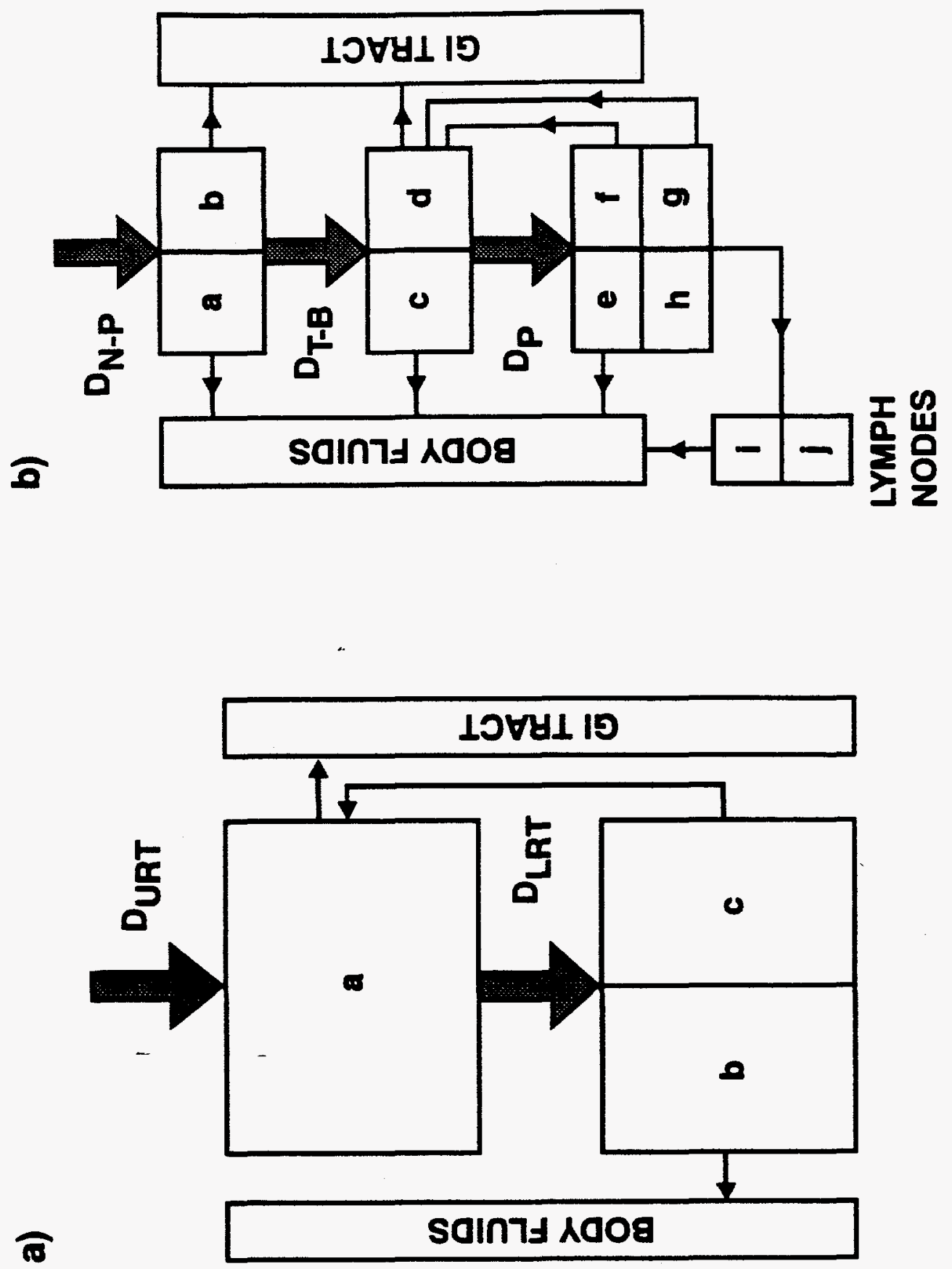


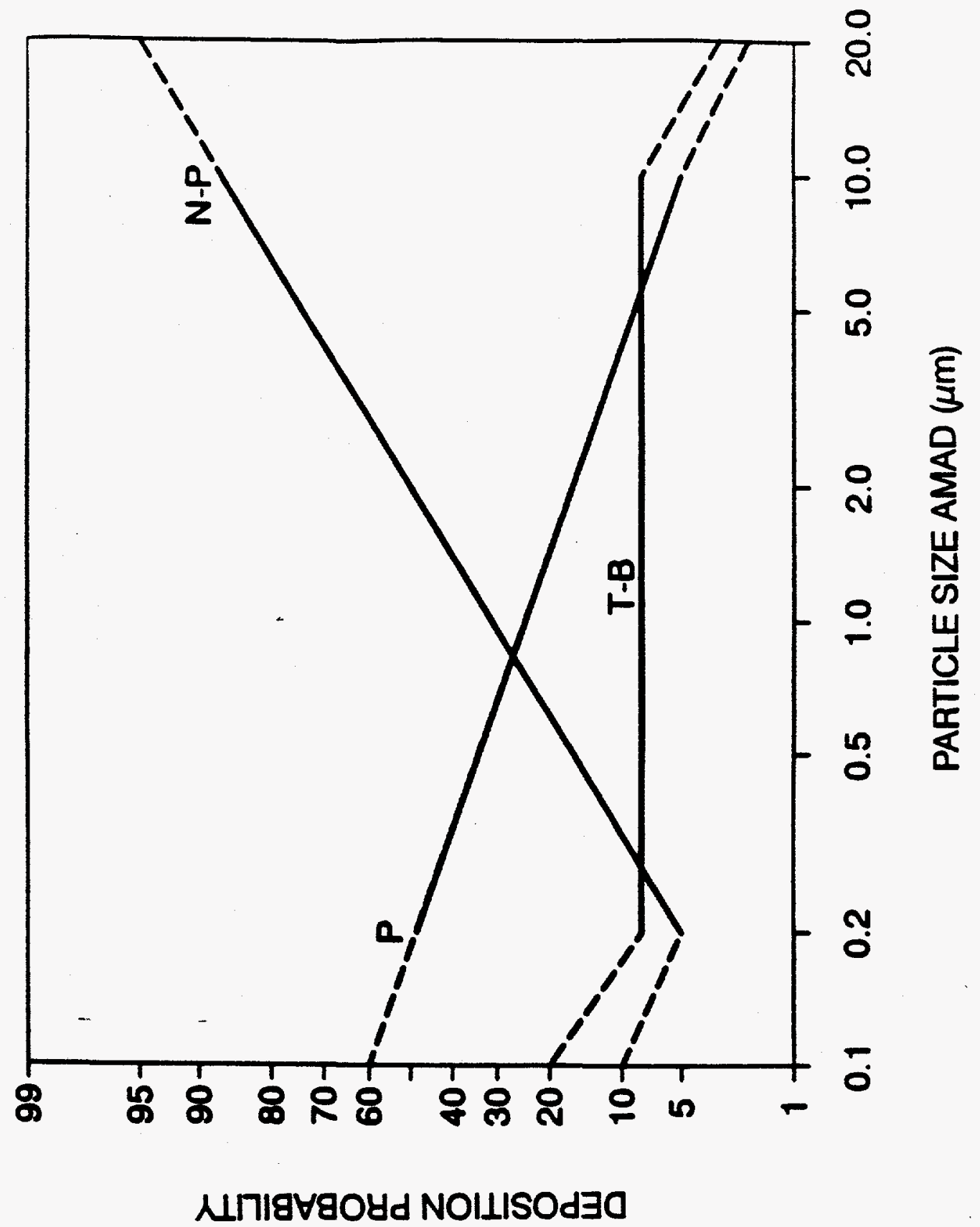



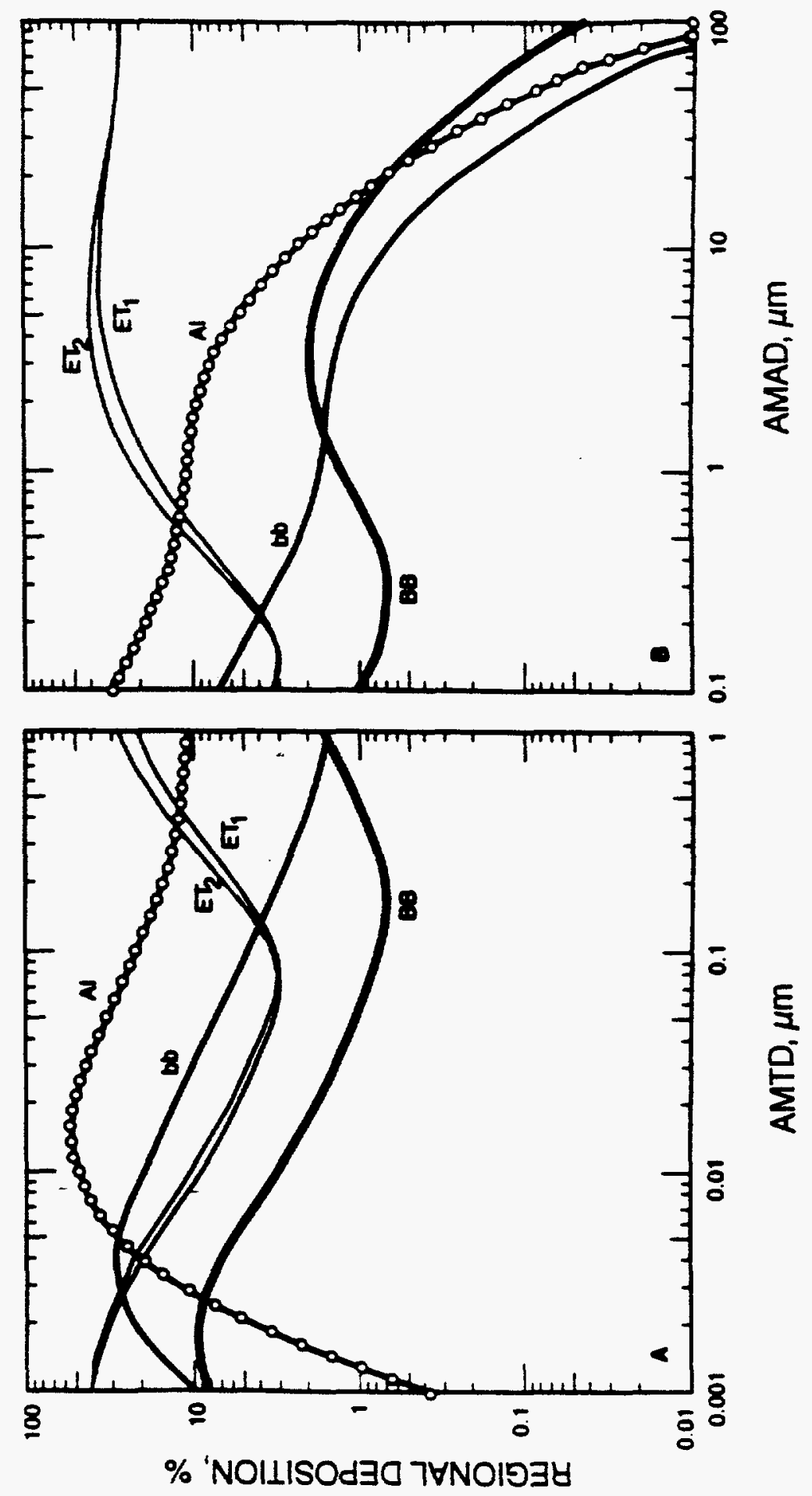


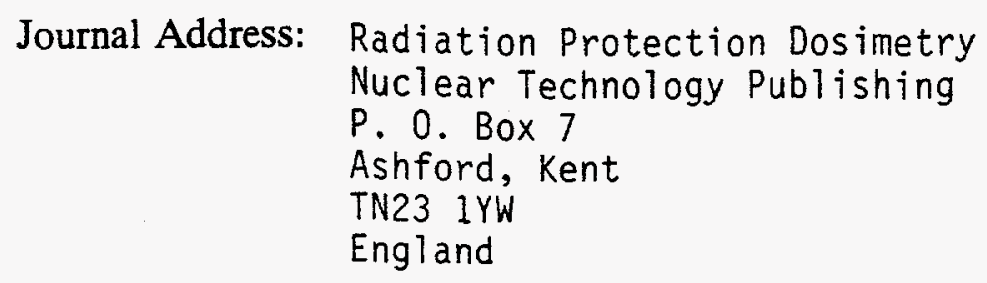

Title of Paper: Comparison of 01d and New ICRP Models for Respiratory Tract Dosimetry

Name and Affiliation Bruce B. Boecker of Principal Authors:

Inhalation Toxicology Research Institute, Lovelace Biomedical and Environmental Research Institute, P.O. Box 5890, Albuquerque, NM 87185

\section{U.S. Government Contractor Statement}

The submitted manuscript has been authored by a contractor, Lovelace Biomedical and Environmental Research Institute, of the U.S. Government under Department of Energy Contract Number DE-AC04-76EV01013. Accordingly, the U.S. Government retains nonexclusive royaltyfree license to publish or reproduce the published form of this contribution, or allow others to do so, for U.S. Government purposes.

February 28, 1995

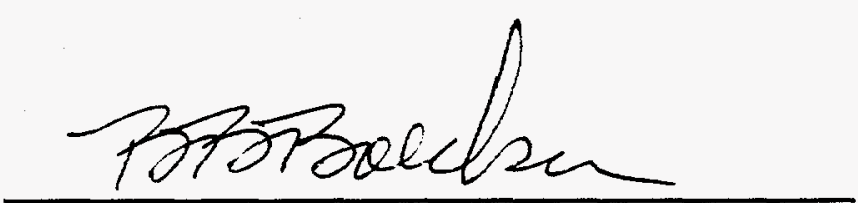

Date 